\title{
Direct costs of inequalities in health care utilization in Germany 1994 to 2009: a top-down projection
}

\author{
Lars Eric Kroll ${ }^{*}$ and Thomas Lampert
}

\begin{abstract}
Background: Social inequalities in health are a characteristic of almost all European Welfare States. It has been estimated, that this is associated with annual costs that amount to approximately $9 \%$ of total member state GDP. We investigated the influence of inequalities in German health care utilization on direct medical costs.

Methods: We used longitudinal data from a representative panel study (German Socio-Economic Panel Study) covering 1994 to 2010. The sample consisted of respondents aged 18 years or older. We used additional data from the German Health Interview and Examination Survey for Children and Adolescents, conducted between 2003 and 2006, to report utilization for male and female participants aged from 0 to 17 years. We analyzed inequalities in health care using negative binomial regression models and top-down cost estimates.

Results: Men in the lowest income group (less than 60\% of median income) had a 1.3-fold (95\% Cl: 1.2-1.4) increased number of doctor visits and a 2.2-fold ( $95 \% \mathrm{Cl}$ : 1.9-2.6) increased number of hospital days per year, when compared with the highest income group; the corresponding differences were 1.1 (95\% Cl: 1.0-1.1) and 1.3 (95\% Cl: 1.2-1.5) for women. Depending on the underlying scenario used, direct costs for health care due to health inequalities were increased by approximately 2 billion to 25 billion euros per year. The best case scenario (the whole population is as healthy and uses an equivalent amount of resources as the well-off) would have hypothetically reduced the costs of health care by 16 to 25 billion euros per year.

Conclusions: Our findings indicate that inequalities and inequities in health care utilization exist in Germany, with respect to income position, and are associated with considerable direct costs. Additional research is needed to analyze the indirect costs of health inequalities and to replicate the current findings using different methodologies.
\end{abstract}

Keywords: Health care utilization, Health inequalities, Direct costs, Income, Longitudinal data analysis

\section{Background}

Social inequalities in health care are a characteristic of almost all European Welfare States [1]. It is well documented that a lower socioeconomic position is strongly associated with a shorter life expectancy, a higher risk for many chronic diseases, and riskier health behaviors [2]. As a result of these differences in health status, the lower socioeconomic strata have used the health care system more often.

For the analyses of trends regarding inequities in health care utilization, Germany is an especially interesting case. First, Germany has a national health insurance scheme

\footnotetext{
* Correspondence: I.kroll@rki.de

Department of Epidemiology and Health Monitoring, Robert Koch - Institute, Nordufer 20, PO Box 650261 D-13302, Berlin, Germany
}

with very broad coverage and also widespread coverage of public health insurance despite an optional private insurance for high income earners. Second, co-payments for ambulatory doctor consultations were established during the last two decades, but were banned in 2013; recently payments for hospital days and medication have risen [3,4].

Inequalities in health care utilization are well documented in a number of European countries, including Germany [5,6]. Overall, the results of recent studies suggest that compared with more affluent groups, patients from lower socioeconomic groups tend to visit general practitioners (GP's) more often, but have less frequent visits to specialists. Inequalities exist in the probability of contact with a doctor and in regard to the number of

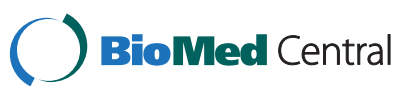


subsequent visits. Taking into account the indicators for medical treatment need and/or severity of the patients' health problems, the 'better off' tend to utilize GPs and specialists more often. With respect to Germany's health care system, the results of international comparative studies suggest that Germany has a medium degree of inequality and inequity $[5,6]$.

From an economic perspective, the persisting inequalities in health and the resulting inequalities in health care have created a sizeable footprint in health expenditures; they also pose risks to the productivity of the national economy. In a recent study, Mackenbach and colleagues tried to evaluate the overall costs of health inequalities for Europe [7]. Based on data for inequalities in mortality and selfrated health in the European Union (EU), these authors concluded that about $20 \%$ of all health care expenditure is due to the poorer health status of lower socioeconomic groups. When also taking productivity losses and social security expenditures into account, the annual costs amount to approximately $9 \%$ of total member state GDP. Following on from this study, further research is needed to qualify whether these results are plausible from a national standpoint, and whether they are persisting over time.

This study aimed to analyze the magnitude and trends of social inequalities in health care utilization in Germany between 1994 and 2009. We used nationally representative data from the German Socio-Economic Panel Study (GSOEP) to analyze the development of increased direct costs caused by health inequalities. We focused on direct costs, because their estimation is, in comparison to the estimation of indirect costs, less dependent on assumptions about lost productivity and/or data on lost life years per social strata (which are not available for Germany). We investigated two consecutive research questions, including (1) the extent of social inequalities within in-patient and outpatient health care, which has been sought in Germany; (2) the costs arising from inequalities in health care.

\section{Methods}

The GSOEP is a longitudinal household panel study that has been conducted annually since 1984 in Western Germany and from 1991 in Eastern Germany [8]. In each participating household, all individuals aged 18 years or older complete a personal questionnaire, typically during spring. The stability of the sample is in excess of $90 \%$ for all subsamples; the proportion of household members interviewed in person is about 94\% [9]. The study covers a wide range of socioeconomic indicators and a small number of health outcomes. The GSOEP population is regularly updated with new survey samples to reflect changes in the German population. The data have previously been used to analyze socioeconomic inequalities in health and health care [4,10-12]. The GSOEP is approved as being in accordance with the standards of the Federal Republic of
Germany for lawful data protection, all participants gave free and informed consent to participate in the survey. The survey ethics are monitored by an independent advisory board at the DIW. We used all the GSOEP waves from 1994 to 2010 . The authors signed a contract with the data holders to permit the use and publishing of data for scientific purposes.

Key demographic information about the study sample is shown in Table 1. According to the recommendations of the data holders, we restricted the analysis to men and women aged 18 and above from households who participated twice in the GSOEP. Overall, 36,179 respondents were observed 274,160 times between 1994 and 2009. The average number of observations per respondent was 5.9

Table 1 Descriptive statistics of the GSOEP sample

\begin{tabular}{|c|c|c|c|c|}
\hline Variable & $\begin{array}{l}\text { Valid } \\
\text { cases }\end{array}$ & $\begin{array}{r}\text { Missing } \\
\text { values }\end{array}$ & Sample & Weighted \\
\hline Gender & & $0.0 \%$ & & \\
\hline Male & 131,408 & & $47.9 \%$ & $47.9 \%$ \\
\hline Female & 142,752 & & $52.1 \%$ & $52.1 \%$ \\
\hline Age & & $0.0 \%$ & & \\
\hline $18-29$ years & 51,134 & & $18.7 \%$ & $16.7 \%$ \\
\hline $30-44$ years & 80,552 & & $29.4 \%$ & $27.3 \%$ \\
\hline 45-64 years & 91,685 & & $33.4 \%$ & $32.4 \%$ \\
\hline 65 years and over & 50,788 & & $18.5 \%$ & $23.6 \%$ \\
\hline Timeframe & & $0.0 \%$ & & \\
\hline 1994-1998 & 63,691 & & $23.2 \%$ & $24.6 \%$ \\
\hline 1999-2003 & 90,993 & & $33.2 \%$ & $24.9 \%$ \\
\hline $2004-2006$ & 61,294 & & $22.4 \%$ & $25.2 \%$ \\
\hline 2007-2009 & 58,182 & & $21.2 \%$ & $25.4 \%$ \\
\hline Income position & & $0.1 \%$ & & \\
\hline$<60 \%$ & 27,790 & & $10.1 \%$ & $12.5 \%$ \\
\hline $60-150 \%$ & 186,273 & & $68.0 \%$ & $68.0 \%$ \\
\hline $150 \%$ and more & 59,808 & & $21.8 \%$ & $19.5 \%$ \\
\hline $\begin{array}{r}\text { Number of doctor visits } \\
\text { per year }\end{array}$ & 261,115 & $4.8 \%$ & 2.6 & 2.8 \\
\hline $\begin{array}{r}\text { Number of days in hospital } \\
\text { per year }\end{array}$ & 249,477 & $9.0 \%$ & 1.8 & 2.8 \\
\hline $\begin{array}{r}\text { Officially acknowledged } \\
\text { disability (yes) }\end{array}$ & 273,107 & $0.4 \%$ & $11.3 \%$ & $13.6 \%$ \\
\hline $\begin{array}{l}\text { General health status } \\
\text { good/very good }\end{array}$ & 273,314 & $0.3 \%$ & $50.0 \%$ & $46.0 \%$ \\
\hline $\begin{array}{l}\text { Satisfaction with } \\
\text { health }(1-10)\end{array}$ & 273,159 & $0.4 \%$ & 6.6 & 6.4 \\
\hline
\end{tabular}

Data: GSOEP 1994-2010.

Valid Cases: Number of cases in category of categorical variable or with nonmissing observations for count variables. Missing Values: Proportion of missing values by variable. Sample: mean or proportion in/of sample; weighted: mean or proportion in/of population as estimated by weighted sample * Data are collected retrospectively in the GSOEP, so a higher number of missing values is inevitable. 
during the study period. The average age of the respondents was 46.9 years; $89.1 \%$ of the study sample had no missing values in any measured indicator, and $94.5 \%$ had no missing values, except for the retrospective indicator for hospital days (see below).

The GSOEP does not allow for the analysis of health care utilization by children and youth. As a consequence, we used additional data from the German Health Interview and Examination Survey for Children and Adolescents (KiGGS 2003-06), conducted between 2003 and 2006, to report utilization for male and female participants aged from 0 to 17 years [13]. The study data have been used to describe socioeconomic inequalities in health status as well as German health care utilization [14,15]. The data include indicators for doctor visits and hospital days, and income position based on their parent's responses; these have been largely comparable with those reported in the GSOEP. Unfortunately, only the first wave of the study is currently available. Because of this, we have calculated the doctor consultations and hospital days by income position, age and gender using KiGGS 2003-06 and used them as approximation for the whole observational period. The sample consisted of 17,641 children (mean age 8.5 years; $50.9 \%$ male). The survey was approved by the Federal Office for Data Protection and by the CharitéUniversitätsmedizin Berlin ethics committee.

The main variable of interest was the household income of the respondents after social transfers. We transformed the variable according to European and German standards for poverty reporting. The at-risk-of-poverty-rate is defined as the percentage of individuals living in households, where the total equalized household income is below $60 \%$ of national equalized median income, after social transfers [16]. We compared three groups including: the at-risk-of-poverty group $(<60 \%$ of the median), the middle income group (60\% to $150 \%$ ), and the relatively well-off (150\% and above). In the KiGGS 2003-06 KiGGS study comparable income information was obtained from the participants' parents.

We used the number of doctor visits and the number of days in a hospital (both measured annually) as indicators for in-patient and out-patient care. The indicator for number of doctor visits per year was based on selfreported doctor consultations during the 3 months prior to the survey, i.e. 'Have you gone to a doctor within the last three months? If yes, please state how often'. The mean number of visits was 2.6 visits (99th percentile $=20$ ); this value was multiplied by four to reflect the annual number of visits. The number of hospital days per year was asked retrospectively in successive (adjacent) panel waves. As a result, we were only able to cover years 1994 to 2009 , although we used GSOEP data up to 2010. These data also had a higher number of missing values owing to the combined effects of item-non-response and drop out in subsequent waves. This indicator was based on two questions: 'How many nights altogether did you spend in the hospital last year?' (mean $=0.168$ nights; 99th percentile $=2$ ) together with 'And how often were you admitted to a hospital in the year [last year]?' (mean $=1.7$ times; 99th percentile $=35$ ). Both counts were summed to obtain the number of hospital days per year. In the KiGGS study, the same questions were used but were answered by the children's parents.

The top-down projection of direct costs resulting from health inequalities was based on two alternative scenarios. The first scenario assumes that the whole population uses the same amount of resources as the highest income group. The second scenario assumes that it is at least possible to reduce the need of the lowest income group to the level of the middle income group. For the top-down projection we estimated the average costs per doctor consultation and per hospital day for the four periods. An average for both sectors was derived from the sum of expenditures divided by the average total number of doctor visits and hospital days. To estimate the totals we used the averages estimated for both indicators (by period, age and gender) and multiplied these by the total number of residents in the respective cells using official population statistics. This top-down approach is a useful instrument to simplify estimations of complex costgenerating processes. Further, we assumed that the direct costs in both sectors were equivalent to the total number of utilizations. The resulting approximations for unit costs are presented in Table 2.

\section{Statistical analyses}

All statistical analyses were based on a pooled dataset, including all panel waves from 1994 to 2010 to allow for trend analysis at the individual and population level. Analyses were performed using STATA 12.0 [17]. The study period was split into four consecutive periods (1994-1998, 1999-2003, 2004-2006, 2007-2009) that are roughly in line with governmental periods in Germany as well as the KiGGS study's observational period (first wave); the number of doctor visits and the number of hospital days were then analyzed by income position, age and gender. Additionally, age-adjusted incidence rate ratios by income were computed using negative binomial regression for count outcomes with overdispersion. Confidence intervals were calculated based on robust Huber-White estimates to control for the data's panel structure $[18,19]$. We then predicted the direct costs of inequalities in health care utilization based on the utilization of doctors and hospitals, and the total amount of costs in the ambulatory and hospital settings. Reference data for the analysis of direct costs were obtained from the Federal Statistical Office of Germany [20]. We used data of the so called 'illness cost assessment' on the total illness costs by sector and year. 
Table 2 Top-down approximation of costs per doctor visit and per hospital day

\begin{tabular}{|c|c|c|c|c|c|c|}
\hline & \multicolumn{2}{|c|}{$\begin{array}{r}\text { Projected utilization based on } \\
\text { GSOEP and KiGGS }\end{array}$} & \multicolumn{2}{|c|}{$\begin{array}{r}\text { Costs per sector according to } \\
\text { Federal Statistical Office }\end{array}$} & \multicolumn{2}{|r|}{ Unit costs } \\
\hline & $\begin{array}{l}\text { Doctor visits } \\
\text { mil. per year }\end{array}$ & $\begin{array}{r}\text { Hospital days } \\
\text { mil. per year }\end{array}$ & $\begin{array}{r}\text { Ambulatory in mil. } \\
\text { euros per year }\end{array}$ & $\begin{array}{l}\text { Clinical in mil. } \\
\text { euros per year }\end{array}$ & $\begin{array}{r}\text { Ambulatory costs } \\
\text { per visit }\end{array}$ & $\begin{array}{r}\text { Clinical costs } \\
\text { per day } \\
\end{array}$ \\
\hline \multicolumn{7}{|l|}{ Period } \\
\hline 1994-1998 & 867.5 & 150.1 & 87,709 & 70,688 & $€ 101.10$ & $€ 470.86$ \\
\hline 1999-2003 & 803.4 & 141.3 & 101,608 & 78,477 & $€ 126.48$ & $€ 555.45$ \\
\hline 2004-2006 & 764.8 & 132.4 & 116,698 & 87,335 & $€ 152.59$ & $€ 659.73$ \\
\hline 2007-2009 & 767.0 & 120.8 & 131,740 & 94,678 & $€ 171.75$ & $€ 783.54$ \\
\hline
\end{tabular}

Data: GSOEP 1994-2010, KiGGS 2003-06, Federal Statistical Office 2011.

\section{Results}

Figure 1 shows the average number of doctor consultations and hospital days per year differentiated by age and gender for 2007 to 2009. Both indicators show a remarkable increase versus the age of the population. Overall, men and women aged 18 years or older visited a doctor an average of 9.2 and 11.3 times, respectively, and spent 1.6 and 1.8 days in hospital per year, respectively. On average, every additional year of age increases the number of doctor consultations per year by $1.5 \%$ for men and by $1.7 \%$ for women, and the number of hospital days per year by $3.5 \%$ for both sexes.
Figures 2 and 3 present the differences in doctor consultations and hospital days per year, for 2007 to 2009, differentiated by income position. During this timeframe, the differences relating to the number of doctor consultations were relatively low. Men in the lowest income group aged 18 years or older, reported 10.0 visits a year to a doctor, while those in the highest income group had 8.5 visits. The differences were especially marked for men aged 45 to 64 years, and also for male children and youths. By contrast, for women, the differences were small for doctor consultations by income. Having controlled for age, adult men and women in the lowest

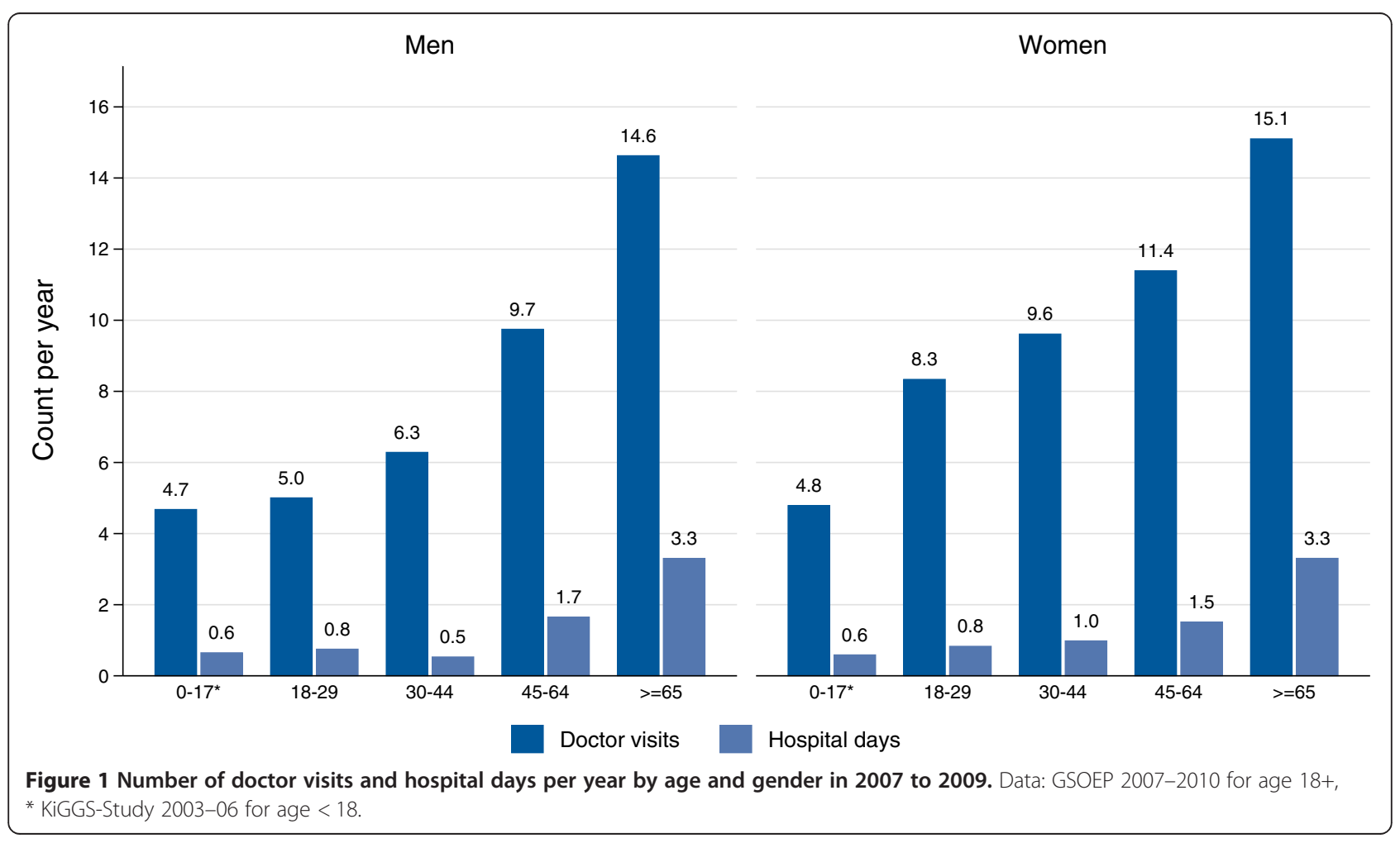




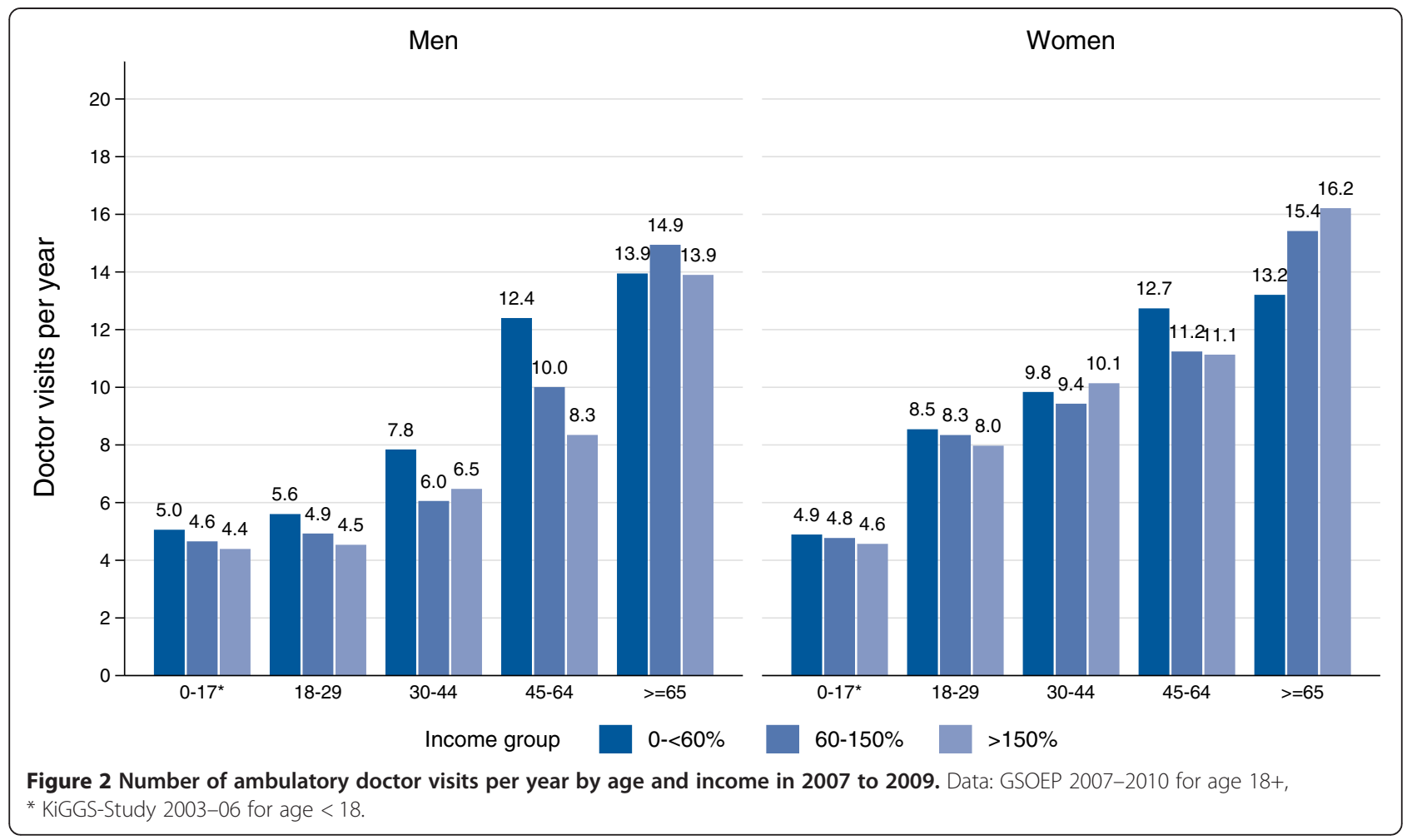

income group had a statistically significant 1.28 -fold and 1.08-fold higher rate of ambulatory visits, respectively, when compared with those in the highest income group (Appendix); men and women also had a 2.22-fold and 1.33-fold higher rate of hospital days per year, respectively, than those in the highest income group (Appendix). The differences for children and youth were analyzed separately using the KiGGS-Study. The corresponding differences were shown to be 1.12-fold and 1.07-fold higher, and 1.85-fold and 2.86-fold higher, respectively (Appendix).

In Table 3, the results of the extrapolation from average health care utilization in the GSOEP and KiGGS to overall health care utilization and costs are presented. We compared the results of the extrapolation with the costs of two alternative scenarios: 1) all income groups share the age and gender specific health status and health care utilization rates of the highest income group; 2) the lowest income group can be leveled with the health status and utilization rates of the middle income group, while the utilization of the middle and high group remains as extrapolated. Overall, the results show that inequalities in health status and health care utilization in Germany are associated with considerable direct costs. The amount of the associated costs depends largely upon the underlying scenario that is used. The best case scenario (i.e. the whole population is as healthy and uses an equivalent amount of resources as the well off) would have hypothetically reduced the costs of health care by 19 to 25 billion euros per year (1.0\% to $1.4 \%$ of German GDP in the respective years). The more realistic scenario (i.e. 'closing the gap' between the poor and middle income groups) would have led to a reduction of a mere 2 to 5 billion euros per year ( $0.1 \%$ to $0.2 \%$ of German GDP in the respective years). The higher costs for men than for women correspond with results for income inequalities in Germany regarding morbidity and mortality, that also tends to be greater for men than for women [21].

\section{Discussion}

The aim of this study was to provide trends and cost scenarios for inequalities in health care utilization in Germany between 1994 and 2009. Overall, the results show that populations in Germany with low disposable incomes are using in-patient and out-patient health care more frequently than parts of the population who are better off. Every year, considerable costs are associated with the increased care needs of people who belong to an income group that is at risk of poverty. However, the results of the costs projections are based on the assumption that doctor visits and hospital days can be treated as indicators to estimate costs in the ambulatory and the hospital sector, which limits their generalizability.

The results presented here are in line with previous studies on inequalities in health care in Germany [22]. The main area of interest for previous studies was the number 


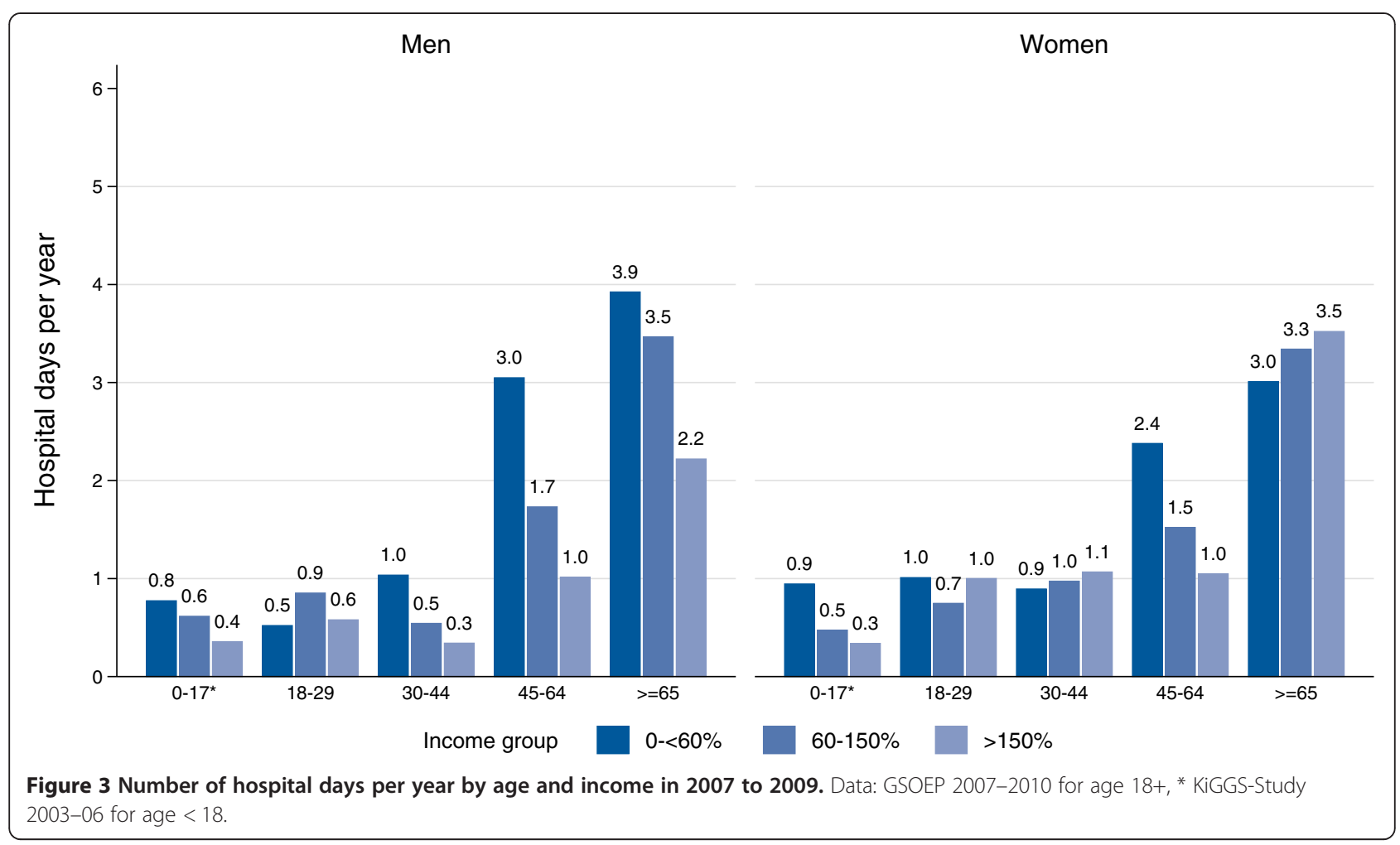

of doctor consultations comparing general practitioners and specialists [23-28]. These studies have shown that men and women with a lower socioeconomic status have more consultations than those with a higher status. Results of international comparative studies that have included
Germany also have shown that the magnitude of inequities is near the average of other developed market economies $[5,6]$. Currently, there are only limited data on direct costs of health inequalities, notwithstanding the study of Mackenbach and colleagues [7]. In Germany, a study using

Table 3 Extrapolation of absolute numbers and simulation of costs for ambulatory and hospital care

\begin{tabular}{|c|c|c|c|c|c|c|c|c|}
\hline & \multicolumn{2}{|c|}{$\begin{array}{l}\text { Extrapolation of } \\
\text { empirical values }\end{array}$} & \multicolumn{3}{|c|}{$\begin{array}{l}\text { Change in direct costs: } \\
\text { Scenario I (all like 150\%) }\end{array}$} & \multicolumn{3}{|c|}{$\begin{array}{l}\text { Change in direct costs: } \\
\text { Scenario II }(<60 \% \text { like } 60-150 \%)\end{array}$} \\
\hline & $\begin{array}{l}\text { Doctor visits in } \\
\text { mil. per year }\end{array}$ & $\begin{array}{l}\text { Hospital days } \\
\text { mil. per year }\end{array}$ & $\begin{array}{r}\text { Ambulatory in } \\
\text { mil. euros }\end{array}$ & $\begin{array}{r}\text { Hospitals in } \\
\text { mil. euros }\end{array}$ & $\begin{array}{l}\text { Overall in } \\
\text { mil. euros }\end{array}$ & $\begin{array}{r}\text { Ambulatory in } \\
\text { mil. euros }\end{array}$ & $\begin{array}{r}\text { Hospitals in } \\
\text { mil. euros }\end{array}$ & $\begin{array}{l}\text { Overall in } \\
\text { mil. euros }\end{array}$ \\
\hline \multicolumn{9}{|l|}{ Men } \\
\hline 1994-1998 & 355.8 & 65.3 & $-3,985$ & $-10,893$ & $-14,878$ & -322 & -967 & $-1,288$ \\
\hline 1999-2003 & 336.6 & 64.9 & $-3,005$ & $-9,112$ & $-12,117$ & -132 & -958 & $-1,089$ \\
\hline $2004-2006$ & 326.5 & 62.7 & $-5,859$ & $-15,131$ & $-20,990$ & -824 & $-1,714$ & $-2,537$ \\
\hline 2007-2009 & 332.3 & 55.7 & $-4,167$ & $-15,460$ & $-19,627$ & -755 & $-1,431$ & $-2,186$ \\
\hline \multicolumn{9}{|l|}{ Women } \\
\hline 1994-1998 & 511.7 & 84.8 & -689 & $-2,936$ & $-3,625$ & -618 & $-1,494$ & $-2,112$ \\
\hline 1999-2003 & 466.7 & 76.4 & $-3,189$ & $-3,300$ & $-6,489$ & -554 & -198 & -753 \\
\hline $2004-2006$ & 438.3 & 69.7 & 1,313 & $-5,028$ & $-3,714$ & -454 & $-2,324$ & $-2,778$ \\
\hline $2007-2009$ & 434.8 & 65.2 & 1,496 & $-2,140$ & -644 & 146 & $-1,231$ & $-1,085$ \\
\hline \multicolumn{9}{|l|}{ Both } \\
\hline 1994-1998 & 867.5 & 150.1 & $-4,674$ & $-13,829$ & $-18,502$ & -939 & $-2,461$ & $-3,400$ \\
\hline 1999-2003 & 803.4 & 141.3 & $-6,194$ & $-12,412$ & $-18,607$ & -686 & $-1,156$ & $-1,842$ \\
\hline $2004-2006$ & 764.8 & 132.4 & $-4,546$ & $-20,159$ & $-24,705$ & $-1,277$ & $-4,038$ & $-5,315$ \\
\hline 2007-2009 & 767.0 & 120.8 & $-2,671$ & $-17,600$ & $-20,271$ & -609 & $-2,662$ & $-3,271$ \\
\hline
\end{tabular}

Data: SOEP 1994-2010, KiGGS 2003-06, Federal Statistical Office (2011a,b). 
health insurance company data showed that during the late 1990s, expenditure per insured person varied significantly depending on their personal income [29]. An increase in annual income of 5,000 euros-with age, sex, marital and disability status held constant-lowered the annual expenditure by approximately 175 euros.

In contrast to studies that are based on insurance data, this study used self-reported health care utilization and a top-down approximation of associated costs. The study has several limitations owing to the method of cost estimation and the dataset. To obtain sufficient file sizes for the analysis of time trends involving consultations, we opted to combine study data covering several years to maximize the statistical power for the cost estimation. The data from the GSOEP did not allow us to distinguish the number of visits to general practitioners and specialists; this would have been desirable because the methodology would have aligned with previous research approaches. A linkage between the survey data about socioeconomic position and process data on expenditures for each study member was not possible owing to the strict data protection laws in Germany. Additionally, we had to use data from the KiGGS-Study conducted in 2003 to 2006 for all periods compared. Therefore, our cost projections aren't able to cover changes in inequalities in health care utilization among children and youth.

In order to assess the plausibility of the extrapolation and simulation regarding the costs of health inequalities, we compared the extrapolation results using absolute numbers of doctor consultations and hospital days with data from the Federal Statistical Office. It is known that self-reports about doctor consultations in Germany tend to underestimate the number of billed consultations. This is due to peculiarities of the medical system, where a physical visit to a doctor often leads to several billed contacts for that particular doctor in the books of the health insurance company [30]. Based on the GSOEP data for the time period 2007 to 2009, the average person in Germany had 10.4 doctor visits per year. In contrast, Barmer GEK, one of the largest German health insurance companies, had an average 18.7 contacts recorded in their files; this results in an underestimation of billed contacts by about $44 \%$ when using self-reports. An underestimation is also present for hospital days; the absolute numbers can be obtained by using hospital statistics of the Federal Statistical Office [31]. According to this Office, Germans spent a total of 142.4 million days in hospital in 2009, while the extrapolation of the GSOEP data computed 120.6 million days for 2007 to 2009 , or approximately $15 \%$ less. In our opinion, this underestimation of doctor visits in the GSOEP should be regarded as negligible, because it is a systematic error that influences the absolute number of visits in all income groups in the same way, and hence not the relative differences between them. On the other hand, the underestimation of hospital days is likely to have influenced the results. Based on the analysis of panel mortality in the GSOEP, it is known that hospital days and a low socioeconomic status are positively associated with panel attrition [32]. Therefore, it can be argued that the observed differences between the income groups are conservative, in relation to the hospital days and resulting cost projections, because they underestimate the situation within the population.

\section{Conclusions}

This study shows that inequalities in health have a major impact on the health care system in Germany and that they produce considerable costs for the sector. Despite an overall reduction in the number of age-specific doctor visits and hospital days over the last 15 years, inequalities were observed in all time periods that were analyzed. It is increasingly acknowledged that health inequality is avoidable and not a restricted trait of modern welfare states [2]. Therefore, the results of this study are a reminder for the need of an effective policy to close the health gap.

It would have been better to have had available more specific estimates of the direct costs of health inequalities in Germany, which could have been based on health insurance company data. Additional research is also needed to analyze the indirect costs of health inequalities in this country. In Germany, the key problem affecting this research area is the limited availability of data about socioeconomic differences in mortality. In relation to the results on inequities in out-patient care, their reasons and structural determinants should be investigated further in order to ensure that every patient receives the correct amount of treatment they need.

\section{Ethical approval}

This study used anonymized secondary data of scientific use files, no ethical approval was needed.

\section{Appendix}

In Tables 4 and 5 results negative binomial regression models for determinants of doctor visits and hospital days are shown. The models are controlled for age, adult men and women in the lowest income group had a statistically significant 1.28-fold and 1.08-fold higher rate of ambulatory visits, respectively, when compared with those in the highest income group; men and women also had a 2.22fold and 1.33-fold higher rate of hospital days per year, respectively, than those in the highest income group (Table 4). The differences for children and youth were analyzed separately using the KiGGS-Study. The corresponding differences were shown to be 1.12-fold and 1.07-fold higher, and 1.85-fold and 2.86-fold higher, respectively (Table 5). 
Table 4 Negative binomial regression model for doctor visits and hospital days (adults)

\begin{tabular}{|c|c|c|c|c|c|c|c|c|}
\hline \multirow[b]{3}{*}{ Age } & \multicolumn{4}{|c|}{ Men $(n=112,800)$} & \multicolumn{4}{|c|}{ Women $(n=123,365)$} \\
\hline & \multicolumn{2}{|c|}{ Doctor visits } & \multicolumn{2}{|c|}{ Hospital days } & \multicolumn{2}{|c|}{ Doctor visits } & \multicolumn{2}{|c|}{ Hospital days } \\
\hline & OR & $95 \%-\mathrm{Cl}$ & OR & $95 \%-\mathrm{Cl}$ & OR & $95 \%-\mathrm{Cl}$ & OR & $95 \%-\mathrm{Cl}$ \\
\hline $18-29$ & Ref. & & Ref. & & Ref. & & Ref. & \\
\hline $30-44$ & $1.20^{*}$ & {$[1.14,1.26]$} & 1.21 & {$[0.94,1.52]$} & $1.10^{*}$ & {$[1.06,1.14]$} & 1.09 & {$[0.97,1.23]$} \\
\hline $45-64$ & $1.98^{*}$ & {$[1.88,2.07]$} & $2.97^{*}$ & {$[2.38,3.70]$} & $1.40^{*}$ & {$[1.35,1.45]$} & $1.59^{*}$ & {$[1.42,1.77]$} \\
\hline$\geq 65$ & $2.82^{*}$ & {$[2.69,2.96]$} & $5.79^{*}$ & {$[4.62,7.25]$} & $1.88^{*}$ & {$[1.82,1.95]$} & $3.52^{*}$ & {$[3.17,3.89]$} \\
\hline \multicolumn{9}{|l|}{ Time period } \\
\hline 1994-1998 & Ref. & & Ref. & & Ref. & & Ref. & \\
\hline 1999-2003 & $0.92^{*}$ & {$[0.88,0.95]$} & 0.96 & {$[0.86,1.07]$} & $0.89^{*}$ & {$[0.87,0.92]$} & $0.87^{*}$ & {$[0.80,0.94]$} \\
\hline 2004-2006 & $0.86^{*}$ & {$[0.82,0.89]$} & $0.85^{*}$ & {$[0.75,0.98]$} & $0.82^{*}$ & {$[0.79,0.84]$} & $0.75^{*}$ & {$[0.68,0.83]$} \\
\hline 2007-2009 & $0.86^{*}$ & {$[0.83,0.90]$} & $0.73^{*}$ & {$[0.62,0.85]$} & $0.81^{*}$ & {$[0.79,0.84]$} & $0.71^{*}$ & {$[0.64,0.78]$} \\
\hline \multicolumn{9}{|l|}{ Income position } \\
\hline$<60 \%$ & $1.28^{*}$ & {$[1.20,1.37]$} & $2.22^{*}$ & {$[1.91,2.58]$} & $1.08^{*}$ & {$[1.03,1.12]$} & $1.33^{*}$ & {$[1.19,1.50]$} \\
\hline $60 \%-<150 \%$ & $1.14^{*}$ & {$[1.11,1.18]$} & $1.56^{*}$ & {$[1.41,1.73]$} & 1.01 & {$[0.98,1.04]$} & $1.13^{*}$ & {$[1.03,1.23]$} \\
\hline$\geq 150 \%$ & Ref. & & Ref. & & Ref. & & Ref. & \\
\hline \multicolumn{9}{|l|}{ Statistics } \\
\hline chi2 & & 3,125 & & 1,079 & & 2,076 & & 1,110 \\
\hline $\mathrm{p}$ & & 0.000 & & 0.000 & & 0.000 & & 0.000 \\
\hline
\end{tabular}

Data: SOEP 1994-2010.

OR Odds ratios [ $95 \% \mathrm{Cl}$ ]: $95 \%$ confidence interval of the odds ratios based on robust standard errors. Ref.: reference category of indicator variables. All indicator variables are coded $0=$ no and $1=$ yes. $p$ represents the $\mathrm{p}$ value for the likelihood-ratio test for the respective model, chi2 is the corresponding chi2 test, $\mathrm{n}$ the number of observations. ${ }^{*} \mathrm{p}<0.05$.

Table 5 Negative binomial regression model for doctor visits and hospital days (children)

\begin{tabular}{|c|c|c|c|c|c|c|c|c|}
\hline & \multicolumn{4}{|c|}{ Boys $(n=8,260)$} & \multicolumn{4}{|c|}{ Girls $(n=8,004)$} \\
\hline & \multicolumn{2}{|c|}{ Doctor visits } & \multicolumn{2}{|c|}{ Hospital days } & \multicolumn{2}{|c|}{ Doctor visits } & \multicolumn{2}{|c|}{ Hospital days } \\
\hline & OR & $95 \%-\mathrm{Cl}$ & OR & $95 \%-\mathrm{Cl}$ & OR & $95 \%-\mathrm{Cl}$ & OR & $95 \%-\mathrm{Cl}$ \\
\hline \multicolumn{9}{|l|}{ Age } \\
\hline $0-2$ & $1.80^{*}$ & [1.69.1.92] & $2.47^{*}$ & {$[1.55 .3 .94]$} & $1.77^{*}$ & {$[1.66 .1 .89]$} & $2.70^{*}$ & {$[1.64 .4 .45]$} \\
\hline $3-6$ & $1.55^{*}$ & [1.46.1.65] & 0.90 & {$[0.59 .1 .36]$} & $1.41^{*}$ & [1.33.1.50] & 1.06 & {$[0.67 .1 .66]$} \\
\hline $7-10$ & $1.08^{*}$ & [1.02.1.15] & 1.07 & {$[0.70 .1 .63]$} & 1.02 & [0.97.1.09] & 1.28 & [0.82.2.00] \\
\hline $11-13$ & Ref. & & Ref. & & Ref. & & Ref. & \\
\hline $14-17$ & $1.10^{*}$ & [1.04.1.17] & 1.27 & [0.83.1.92] & $1.43^{*}$ & {$[1.35 .1 .51]$} & $2.94^{*}$ & [1.90.4.54] \\
\hline \multicolumn{9}{|l|}{ Income position } \\
\hline$<60 \%$ & $1.12^{*}$ & {$[1.05 .1 .21]$} & $1.85^{*}$ & [1.12.3.06] & $1.07^{*}$ & [1.00.1.15] & $2.86^{*}$ & [1.68.4.88] \\
\hline $60 \%-<150 \%$ & 1.05 & [0.99.1.12] & 1.48 & {$[0.93 .2 .36]$} & 1.04 & [0.98.1.11] & 1.18 & [0.72.1.92] \\
\hline$\geq 150 \%$ & Ref. & & Ref. & & Ref. & & Ref. & \\
\hline \multicolumn{9}{|l|}{ Statistics } \\
\hline chi2 & 566 & 35 & 486 & 66 & & & & \\
\hline$p$ & 0.000 & 0.000 & 0.000 & 0.000 & & & & \\
\hline
\end{tabular}

Data: KiGGS 2003-06.

OR Odds ratios [95\% Cl]: $95 \%$ confidence interval of the odds ratios based on robust standard errors. Ref.: reference category of indicator variables. All indicator variables are coded $0=$ no and $1=$ yes. Under regression diagnostics, $p$ represents the $p$ value for the likelihood-ratio test for the respective model. ${ }^{*} p<0.05$. 


\section{Competing interests}

The authors declare that they have no competing interest.

\section{Authors' contributions}

LEK planned and wrote the first version of the manuscript and did all the statistical analysis. TL assisted in planning the manuscript and the analysis and revised the first draft of the manuscript. Both authors read and approved the final manuscript.

\section{Acknowledgments}

The Robert Koch - Institute is a Federal Institute and primarily funded by the German Ministry of Health (BMG). No special funding was received for this study. The authors wish to thank the reviewers for their valuable contributions in improving the manuscript.

Received: 19 December 2012 Accepted: 3 July 2013

Published: 12 July 2013

\section{References}

1. Mackenbach JP, Stirbu I, Roskam A-JR, Schaap MM, Menvielle G, Leinsalu M, Kunst $A E$, the European Union Working Group on Socioeconomic Inequalities in Health: Socioeconomic inequalities in health in 22 European Countries. N Engl J Med 2008, 358:2468-2481.

2. WHO Commission on Social Determinants of Health: World health organization: closing the gap in a generation: health equity through action on the social determinants of health: commission on social determinants of health final report. Geneva, Switzerland: World Health Organization, Commission on Social Determinants of Health; 2008.

3. Busse R, Riesberg A: Health care systems in transition: Germany. Copenhagen: WHO Regional Office for Europe; 2004.

4. Schreyogg J, Grabka MM: Copayments for ambulatory care in Germany: a natural experiment using a difference-in-difference approach. Eur J Health Econ 2010, 11:331-341.

5. Doorslaer E, Koolman X, Jones AM: Explaining income-related inequalities in doctor utilisation in Europe. Heal Econ 2004, 13:629-647.

6. van Doorslaer E, Masseria C, Koolman X, Group ft OHER: Inequalities in access to medical care by income in developed countries. Canadian Med Assoc J 2006, 174:177-183.

7. Mackenbach JP, Meerding WJ, Kunst AE: Economic costs of health inequalities in the European Union. J Epidemiol Commun Health 2011, 65:412-419.

8. Wagner GG, Frick JR, Schupp J: The German socio-economic panel study (SOEP) - scope, evolution and enhancements. Schmollers Jahr 2007, 127:139-169.

9. SOEP 2006 Method Report: http://www.diw.de/documents/ dokumentenarchiv/17/83168/meth_2006.pdf.

10. Frijters P, Haisken-DeNew JP, Shields MA: The causal effect of income on health: evidence from German reunification. J Heal Econ 2005, 24:997-1017.

11. Nolte E, McKee M: Changing health inequalities in east and west Germany since unification. Soc Sci Med 2004, 58:119.

12. Kroll LE, Lampert T: Changing health inequalities in Germany from 1994 to 2008 between employed and unemployed adults. Int J Public Health 2011, 56:329-339.

13. Kurth BM, Kamtsiuris P, Holling H, Schlaud M, Dolle R, Ellert U, Kahl H, Knopf $H$, Lange $M$, Mensink GB, et al: The challenge of comprehensively mapping children's health in a nation-wide health survey: design of the German KiGGS-study. BMC Publ Health 2008, 8:196.

14. Lampert T, Kurth B-M: Socioeconomic status and health in children and adolescents - results of the german health interview and examination survey for children and adolescents (KiGGS). Deutsches Ärzteblatt 2007, 104:A-2944.

15. Kamtsiuris $P$, Bergmann E, Rattay $P$, Schlaud M: Use of medical services. Results of the german health interview and examination survey for children and adolescents (KiGGS) [in german]. Bundesgesundheitsblatt Gesundheitsforschung Gesundheitsschutz 2007, 50:836-850.

16. Income and living conditions: http://epp.eurostat.ec.europa.eu/cache/ ITY_SDDS/EN/ilc_esms.htm.

17. StataCorp: Stata statistical software: release 12.0. College Station, TX: Stata Corporation; 2011.

18. White H: Maximum likelihood estimation of misspecified models. Econometrica 1982, 50:1-25.
19. Huber PJ: The behavior of maximum likelihood estimates under nonstandard conditions. In Proceedings of the fifth berkeley symposium on mathematical statistics and probability. Berkeley: University of California Press; 1967:221-233.

20. Destatis: Gesundheitsausgabenrechnung. Methoden und Grundlagen 2008. Wiesbaden: Statistisches Bundesamt; 2011.

21. Guntheroth WG, Spiers PS: The triple risk hypotheses in sudden infant death syndrome. Pediatrics 2002, 110:e64.

22. Janßen C, Grosse Frie K, Ommen O: Sozial Ungleichheit und gesundheitsbezogene Versorgung. In Gesundheitliche ungleichheit grundlagen, probleme, konzepte. 2. Überarbeitete auflage. Edited by Richter M, Hurrelmann K. Wiesbaden: VS-Verlag; 2009:141-155.

23. Smythe J, Abholz HH, Alves B, Blane D, Borgers D: Soziale Ungleichheit im Zugang zur ambulanten Behandlung in England und Deutschland. Z Allg Med 2004, 80:58,62.

24. Winkelmann R: Health care reform and the number of doctor visits-an econometric analysis. J Appl Econ 2004, 19:455-472.

25. Winkelmann R: Co-payments for prescription drugs and the demand for doctor visits - evidence from a natural experiment. Heal Econ 2004, 13:1081-1089.

26. Bergmann E, Kamtsiuris P: Inanspruchnahme medizinischer Leistungen. Das Gesundheitswesen 1999, 61:138-144. Sonderheft 2.

27. Thode N, Bergmann E, Kamtsiuris P, Kurth BM: Einflussfaktoren auf die ambulante Inanspruchnahme in Deutschland. Bundesgesundheitsblatt Gesundheitsforschung Gesundheitsschutz 2005, 48:296-306.

28. Bergmann E, Kalcklösch M, Tiemann F: Inanspruchnahme des Gesundheitswesens. BundesgesundheitsblattGesundheitsforschung 2005, 48:1365-1373.

29. Breyer $F$, Heineck $M$, Lorenz $N$ : Determinants of health care utilization by German sickness fund members-with application to risk adjustment. Health Econ 2003, 12:367-376.

30. von Maydell B, Kosack T, Repschläger U, Sievers C, Zeljar R: Achtzehn Arztkontakte im Jahr Hintergründe und Details. In Gesundheitswesen aktuell 2010. Edited by Repschläger U, Schulte C, Osterkamp N. Düsseldorf: Barmer GEK; 2010:176-191.

31. Böhm K: Gesundheitszustand der Bevölkerung und Ressourcen der Gesundheitsversorgung. In Datenreport 2011: Der sozialbericht für Deutschland. Edited by Destatis WZB. Wiesbaden: Bundeszentrale für politische Bildung; 2011:215-239.

32. Kroh M: Documentation of sample sizes and panel attrition in the German socio economic panel (SOEP) (1984 until 2010). DIW Berlin Data Doc 2011, 59:1-47.

doi:10.1186/1472-6963-13-271

Cite this article as: Kroll and Lampert: Direct costs of inequalities in health care utilization in Germany 1994 to 2009: a top-down projection. BMC Health Services Research 2013 13:271.

\section{Submit your next manuscript to BioMed Central and take full advantage of:}

- Convenient online submission

- Thorough peer review

- No space constraints or color figure charges

- Immediate publication on acceptance

- Inclusion in PubMed, CAS, Scopus and Google Scholar

- Research which is freely available for redistribution 